\title{
Research Paper: Pathology Large set data mining reveals overexpressed GPCRs in prostate and breast cancer: potential for active targeting with engineered anti-cancer nanomedicines
}

\author{
Eric Kübler $^{1}$ and Hugo Albrecht ${ }^{2}$ \\ ${ }^{1}$ Institute for Chemistry and Bioanalytics, School of Life Sciences, University of Applied Sciences and Arts Northwestern \\ Switzerland, Muttenz 4132, Switzerland \\ ${ }^{2}$ Centre for Pharmaceutical Innovation and Development, Centre for Drug Discovery and Development, Sansom Institute \\ for Health Research, School of Pharmacy and Medical Sciences, University of South Australia, Adelaide, SA 5001, Australia \\ Correspondence to: Hugo Albrecht, email: hugo.albrecht@unisa.edu.au \\ Keywords: GPCR; cancer; nanocarrier; meta-data; targeted chemotherapy; Pathology \\ Received: March 01, $2018 \quad$ Accepted: April 24, $2018 \quad$ Published: May 18, 2018 \\ Copyright: Kübler et al. This is an open-access article distributed under the terms of the Creative Commons Attribution License 3.0 \\ (CC BY 3.0), which permits unrestricted use, distribution, and reproduction in any medium, provided the original author and source \\ are credited.
}

\section{ABSTRACT}

Over 800 G-protein-coupled receptors (GPCRs) are encoded by the human genome and many are overexpressed in tumors. GPCRs are triggered by ligand molecules outside the cell and activate internal signal transduction pathways driving cellular responses. The receptor signals are desensitized by receptor internalization and this mechanism can be exploited for the specific delivery of ligand-linked drug molecules directly into cells. Detailed expression analysis in cancer tissue can inform the design of GPCR-ligand decorated drug carriers for active tumor cell targeting. The active targeting process utilizes ligand receptor interactions leading to binding and in most cases internalization of the ligand-attached drug carrier resulting in effective targeting of cancer cells. In this report public microarray data from the Gene Expression Omnibus (GEO) repository was used to identify overexpressed GPCRs in prostate and breast cancer tissues. The analyzed data confirmed previously known cancer receptor associations and identified novel candidates for potential active targeting. Prioritization of the identified targeting receptors is also presented based on high expression levels and frequencies in cancer samples but low expression in healthy tissue. Finally, some selected examples were used in ligand docking studies to assess the feasibility for chemical conjugation to drug nanocarriers without interference of receptor binding and activation. The presented data demonstrate a large untapped potential to improve efficacy and safety of current and future anti-cancer compounds through active targeting of GPCRs on cancer cells.

\section{INTRODUCTION}

Globally, more than 14 million cancer-related deaths were reported in 2012 and this annual burden is expected to grow to approximately 22 million by 2030 (World Cancer Report 2014, Stewart BW, Wild CW, ISBN 978-92-832-0443-5). Currently available anticancer drugs are inadequate, and there is demand for better formulations to reduce undesirable adverse effects. The major problem with traditional cytotoxic drugs is their poor bio-distribution to tumors leading to toxic side effects against healthy cells. A consequence of this is that the optimal dose often cannot be administered. Additional challenges are posed by low solubility, rapid in vivo breakdown of free drug, and tissue damage on extravasation. Even molecular targeted cancer therapies (e.g. kinase inhibitors) show side effects and lack of selectivity for neoplastic tissue. Potentially, most of these issues can be overcome by delivery of anti-cancer agents with engineered nanoparticles targeting surface proteins which are overexpressed on cancer cells, but show much lower or no expression in healthy tissue [1]. The majority 
of clinically available anti-cancer nano-formulations use passive targeting, exploiting the Enhanced Permeability and Retention Effect (EPR) [2]. In this case, passive diffusion through endothelial fenestrations of tumor tissue lead to a local build-up of nanoparticle concentrations, an effect further enhanced by the lack of efficient lymphatic drainage. However, nanoparticles also accumulate in various organs, mainly liver and spleen, by vascular escape through endothelial fenestrations [3]. To minimize this effect, drug carriers can be functionalized with ligands or antibodies for active targeting of receptors which show overexpression on cancer cells in comparison to healthy tissue. This can both further enhance the anti-cancer potency on solid tumors and reduce toxic side effects on healthy cells.

Tumor cells generally show a characteristic pattern of overexpressed membrane associated proteins such as receptors, membrane transporters and adhesion molecules. G-protein-coupled-receptors are the largest family of trans-membrane receptors and some are known to be overexpressed in prevalent solid tumors. The most intensely studied targeting receptors from the GPCR family are the somatostatin [4-6], cholecystokinin [7, 8], gastrin-releasing peptide (GRP) [9-11], lutein releasing hormone [12, 13], and neurotensin receptors [14, 15]. Considering the number of known GPCR receptor family members, they appear to be under-represented in current research addressing active receptor targeting. We believe that many more GPCR ligands could be exploited to design drug carriers that e.g. trigger receptor internalization and hence nanoparticle and anti-cancer agent delivery directly into endosomal compartments.

In the past most strategies for drug carrier development focused on liposomal, polymeric and inorganic formulations. Doxil/Caelyx was the first FDA approved anti-cancer nanomedicine [16] and in the meantime is one of seven clinically approved liposomal cancer treatments [17]. In contrast, polymer-based formulations have lagged behind, with Abraxane [18] and Genexol-PM [19] the first FDA approved examples in 2005 and 2007, respectively. Efforts to translate various polymer formulations from preclinical setting to clinical application are ongoing [1]. Notably, the use of amphiphilic synthetic and natural diblock copolymers, which self-assemble into nanoparticles has been recently reported [20]. Elastin-like polypeptides (ELP) are an example of natural diblock copolymers that can be genetically engineered with attached peptide ligands, offering a strategy amenable to $>150$ GPCRs (Figure 1A) [21-23]. Alternatively, ligands can also be chemically conjugated with methods analogous to those commonly used with liposomes (Figure 1B).

Here we present the identification of GPCRs overexpressed in primary prostate and breast cancer tissue. The suitability of overexpressed receptors for specific cancer cell targeting with drug nanocarriers was assessed by consideration of the expression levels in cancer vs healthy tissue. Structural insight is given for selected receptors to indicate amenability for chemical conjugation to nanoparticles. Our findings reveal a large untapped potential for GPCR targeting in cancer treatment with engineered drug carriers.

\section{RESULTS}

\section{Collection of gene expression data}

The aim of this study was to analyze prostate and breast cancer tissue for the overexpression of GPCR receptors with the goal of identifying potential targets for active delivery of anti-cancer compounds with GPCRligand guided drug carriers. The public GEO repository was systematically searched with a focus on a single DNA microarray platform to obtain easily compared data. For this purpose, the GPL570 human DNA array (Affymetrix Inc., Santa Clara, CA, USA) containing 54,675 DNA probes covering most of the human transcriptome was selected. The chosen platform represented $>120,000$ samples available from the GEO data base. A list of 755 GPCR genes was compiled from 21 Pfam domains (7tm and GPCR) within the protein family database (http:// pfam.sanger.ac.uk/) and 437 GPCR genes were identified on the GPL570 platform. The 318 genes not found were largely accounted for by olfactory receptors which were not represented on the GPL570 platform. All over, the chosen platform contained $>90 \%$ of all non-olfactory GPCRs, which was considered suitable for the study. An initial search for prostate and breast cancer data sets in the GEO repository limited to the GPL570 platform resulted in 28 and 37 hits, respectively. The data sets were checked for suitability according to the criteria outlined in the methods section and non-informative data sets have been excluded. The final selection of 6 prostate and 5 breast cancer data sets is given in Table 1. Figure 2 shows the selection cascade outlining the applied criteria which lead to the final selection of overexpressed receptors.

\section{Identification of overexpressed GPCRs}

CEL data files were retrieved from the public GEO repository and processed using a robust multi-array (RMA) [24] normalization protocol with the ArrayStar software (DNAStar Inc, Madison, WI, USA). Annotations and attributes were imported automatically from files provided by Affymetrix Inc. (Santa Clara, CA, USA). Overexpressed GPCRs were systematically identified by comparison of samples from cancer and healthy tissues, e.g. metastatic prostate cancer vs benign prostate or breast node metastasis vs normal breast tissue and so forth. For each data set one or more calculations have been performed. A total of 12 calculations were carried out for prostate cancer samples and 8 calculations for breast cancer samples. A representative example (GDS1439) 
for prostate cancer is illustrated with the scatter plot in Figure 3A. In this case 2 calculations were performed, benign vs metastatic tissue and benign vs local primary tissue. The sample numbers for benign, localized primary and metastatic tissue were 6,7 and 6 , respectively, as indicated in brackets of Table 1 . The color coding indicates overexpression in metastatic prostate cancer samples (blue) and overexpression in benign prostate cancer cells (red). All GPCR probes are highlighted as individual white dots. The differential expression was stronger in metastatic prostate cancer samples $\left(R^{2}=0.8734\right)$ in comparison to local primary prostate cancer samples $\left(R^{2}=0.9760\right)$ as shown in the inset of Figure 3A. An additional example is given for breast cancer in Figure $4 \mathrm{~A}$, and in this case the differential expression was similar when normal tissue was compared to node metastasis and invasive ductal carcinoma (IDC) as indicated by very similar $R^{2}$ values of 0.8663 and 0.8657 , respectively.

It was apparent from the scatter plots that the average GPCR expression levels were lower than the total average expression. This has been confirmed by different quartile distributions as shown in the box plots of Figures $3 \mathrm{~B}$ and $4 \mathrm{~B}$.

Overall, 186 GPCR genes were identified with $\geq 1.5$ fold expression in cancer compared to healthy control tissues in at least one calculation. At this stage, genes with more than one corresponding DNA probe on the GPL570 platform but only a single one rendering a positive signal were included. It was assumed that DNA probes with positive signals in multiple cancer tissues will be more significant. Therefore, as additional criteria, only genes with overexpression in at least 4 replica groups of cancer tissue were considered for further analysis. This arbitrary cut-off was applied to discount all genes with overexpression in less than 4 cancer tissue groups, resulting in a reduction of the initial gene set to a total of 42 overexpressed genes, 11 in $\mathrm{PCa}$ (Table 2), 24 in $\mathrm{BrCa}$ (Table 3) and 7 genes in both $\mathrm{PCa}$ and $\mathrm{BrCa}$. The gene symbols, probe IDs and fold increase are summarized in Tables 2 and 3.

Peptide receptors dominated the selected gene set (19 out of 42). This receptor class represents a high potential for active targeting as they bind relatively large ligands with ample opportunity for chemical linking to carriers. Five lipid receptors were identified, interestingly in $\mathrm{BrCa}$ only, and this type of ligand harbors significant potential for conjugation to nanoparticle based drug carriers. A total of 6 small molecule receptors were identified, namely ADORA3, P2RY2 and P2RY10 in BrCa; ADRA2A, ADRB1 and CHRM3 in PCa. It is likely that small ligands

\section{A Diblock copolymer with peptide ligand}

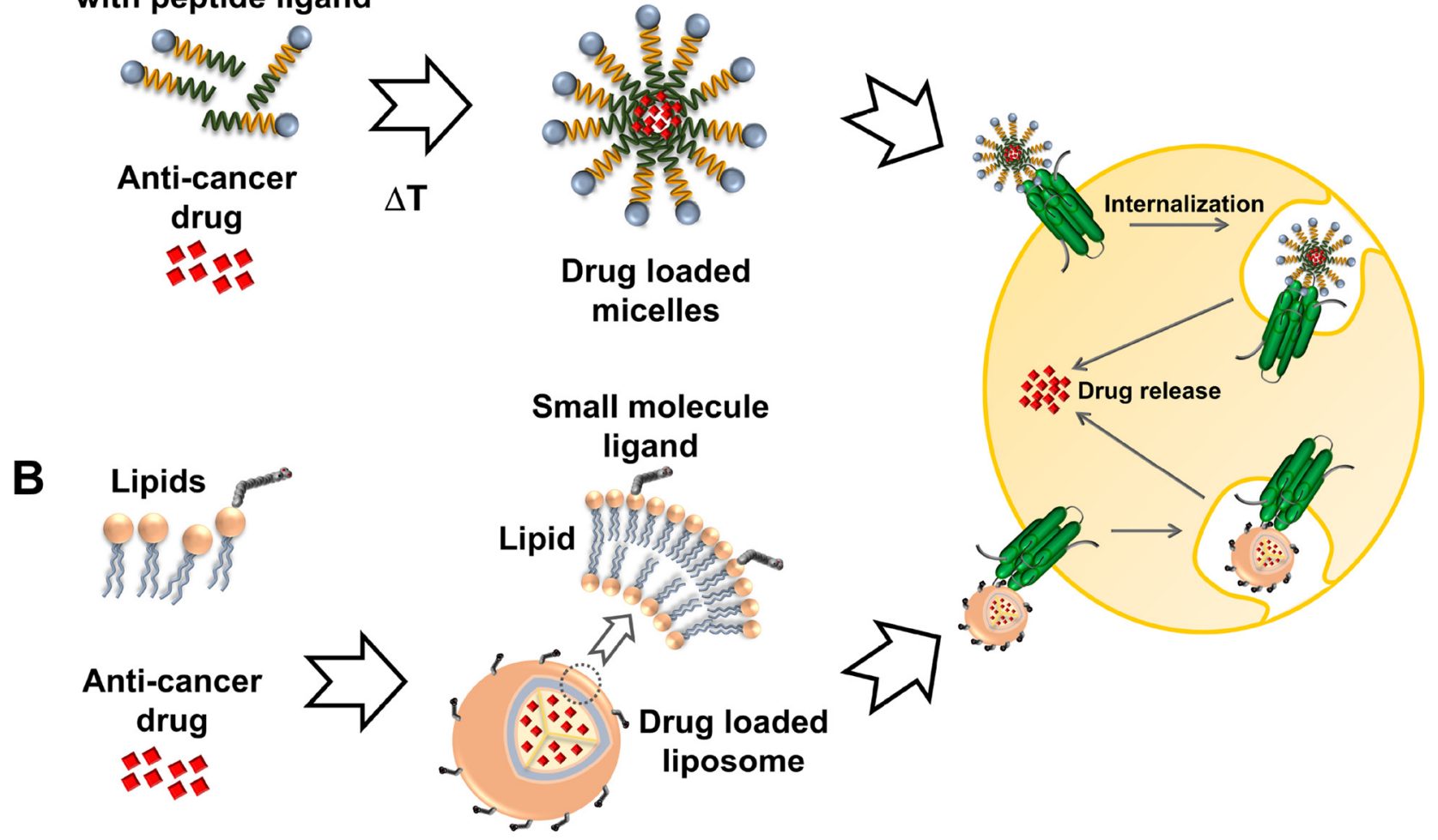

Figure 1: Active targeting of cancer cells. Nanoparticles are decorated with ligands for specific docking to GPCRs overexpressed in cancer cells and driving cellular uptake via receptor internalization. (A) ELPs are self-assembling diblock copolymers which can be engineered as fusion proteins with a tethered peptide ligand (depicted as blue sphere). (B) Small molecule ligands can be covalently attached to lipid components such as phosphatidylcholine for display on the surface of drug loaded liposomes. 
Table 1: Gene expression datasets

\begin{tabular}{|c|c|c|}
\hline Data set accession & $\begin{array}{l}\text { Sample } \\
\text { size }\end{array}$ & Primary cancer samples \\
\hline \multicolumn{3}{|l|}{ Prostate cancer } \\
\hline GDS1439 & 19 & $\begin{array}{l}\text { Benign prostate (6); clinically localized primary (7) and metastatic prostate cancer (6) } \\
{[43]}\end{array}$ \\
\hline GDS4114 & 12 & Normal prostate stroma (6); Stroma associated to prostate invasive tumor (6) [44] \\
\hline GDS4824 & 21 & $\begin{array}{l}\text { Normal benign prostate (8); malignant TMPRSS2:ERG fusion negative (7) and } \\
\text { TMPRSS2:ERG fusion positive (6) [45] }\end{array}$ \\
\hline GSE17951 & 126 & $\begin{array}{l}\text { Control biopsy (17); Radical prostatectomy with } 0 \%(41),<50 \%(38) \text { and }>50 \% \text { tumor } \\
\text { cells (30) [46] }\end{array}$ \\
\hline GSE32448 & 80 & $\begin{array}{l}\text { Normal well differentiated (20) and poorly differentiated }(20)^{1)} \text {; tumor well } \\
\text { differentiated (20) and poorly differentiated (20) [47] }\end{array}$ \\
\hline GSE46602 & 50 & $\begin{array}{l}\text { Tissue from benign prostate glands (10); benign adjacent to prostate cancer (4); prostate } \\
\text { cancer tissue (36) [48] }\end{array}$ \\
\hline \multicolumn{3}{|l|}{ Breast cancer } \\
\hline GSE8977 & 22 & Stroma normal breast (15); stroma tumor (7) [49] \\
\hline GSE22544 & 20 & Normal breast tissue (4); IDC (14); node metastasis (2) [50] \\
\hline GSE29431 & 66 & Normal breast tissue (12); primary breast carcinomas $(54)^{2)}[51]$ \\
\hline GSE42568 & 121 & $\begin{array}{l}\text { Normal breast tissue (17); [IDC (82); invasive lobular (17); tubular (2); mucinous (3) }]^{3)} \\
{[52]}\end{array}$ \\
\hline GSE61304 & 62 & Normal breast epithelium (4); breast tumor epithelium (52) [53] \\
\hline
\end{tabular}

IDC: infiltrating ductal carcinoma; ${ }^{1)}$ poorly differentiated samples were excluded; ${ }^{2}$ these 54 samples were split into 3 groups according to Her2 IHC scores $(0 / 1,2,3)$; ${ }^{3}$ Pooled into 1 group of 104 samples, calculated vs 17 normal samples (1 calculation only for GSE42568); the number of samples are indicated in brackets.

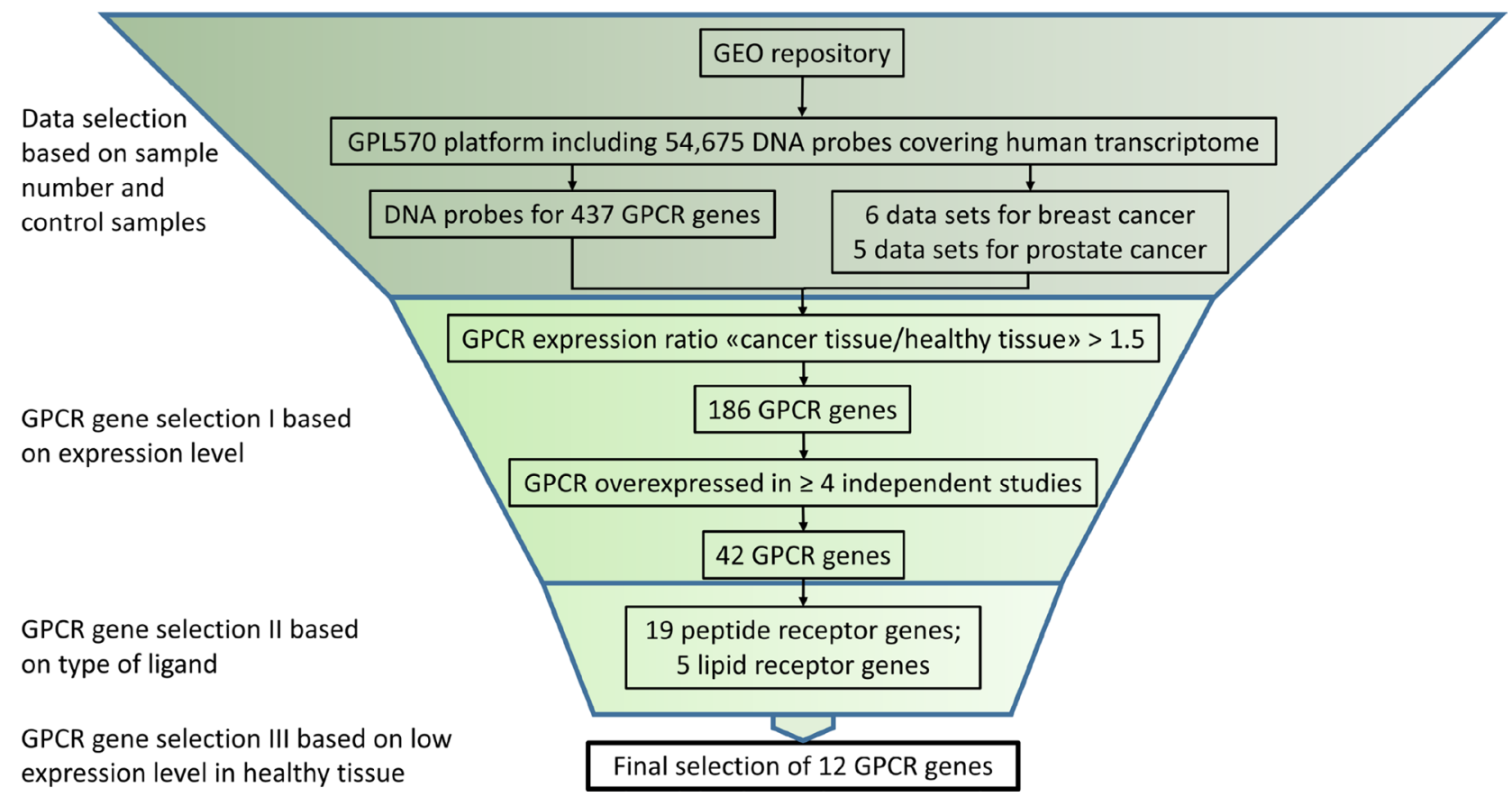

Figure 2: In silico GPCR gene selection algorithm. Suitable GLP570 based data sets were selected and a diverse set of inclusion criteria were applied to select a final set of 12 GPCR genes. 

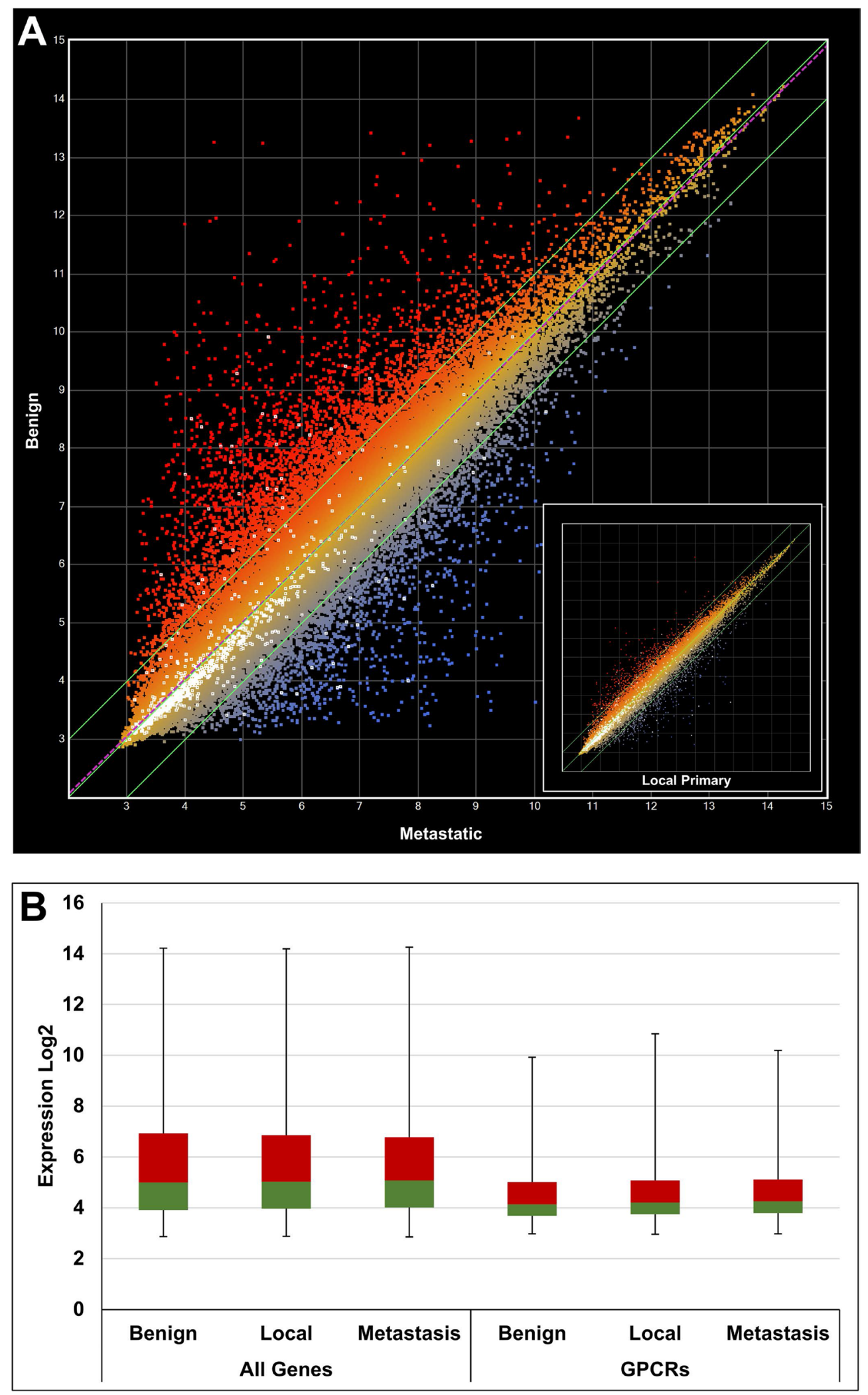

Figure 3: Gene expression analysis using a scatter plot to compare benign, local and metastatic tumor samples from the GDS1439 data set. (A) Benign vs metastatic $\left(R^{2}=0.8734\right)$ and inset showing benign vs primary local $\left(R^{2}=0.9760\right)$. White dots indicate GPCR genes. (B) Box plot comparing expression of all genes vs GPCRs only. The 2 nd and 3rd quartiles are colored in green and red, respectively. The first and fourth quartiles are indicated by error bars. A general lower expression level of GPCR genes can be deduced. 

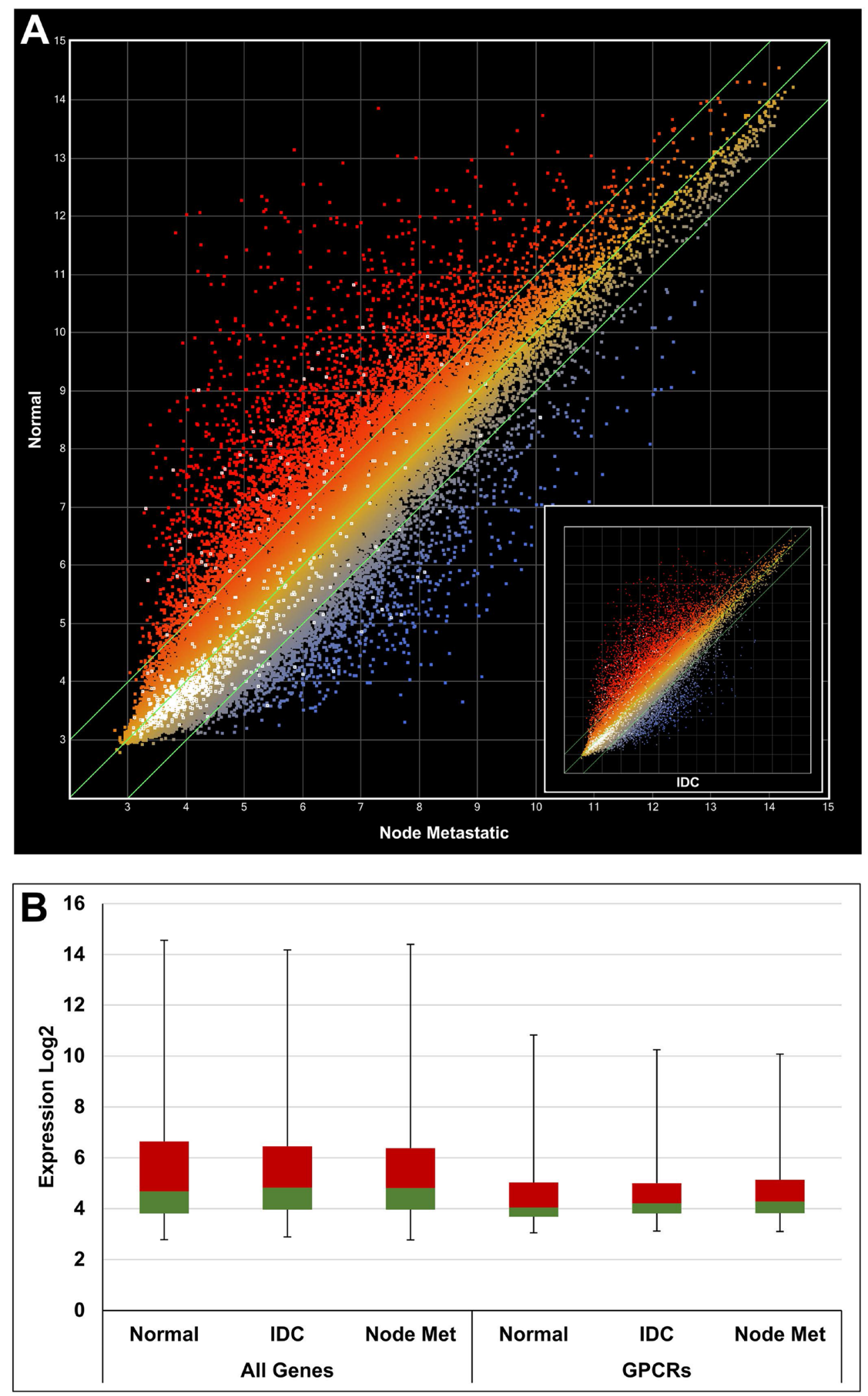

Figure 4: Gene expression analysis using a scatter plot with data from GSE22544. (A) Normal vs node metastasis $R^{2}=0.8663$. Inset: Normal vs IDC $R^{2}=0.8657$. White dots indicate GPCR genes. (B) Box plot comparing expression of all genes vs GPCRs. The 2nd and 3rd quartiles are colored in green and red, respectively. The first and fourth quartiles are indicated by error bars. A general lower expression level of GPCR genes can be deduced. IDC: infiltrating ductal carcinoma. 
Table 2: Overexpression of G-proteins in prostate cancer tissue (min $4 \times>1.5$ fold induction)

\begin{tabular}{|c|c|c|}
\hline Gene & Probe ID & Fold increase ( $p$-Value) \\
\hline \multirow{2}{*}{ ADGRV1 ${ }^{a)}$} & 223582_at & $1.81(0.024), 1.59$ (0.222), $1.73(0.016), 1.95$ (0.016) \\
\hline & 234871_at & $1.67(0.958)$ \\
\hline ADRA2A & 209869_at & 3.39 (0.074), 1.54 (0.539), 1.84 (0.002), 1.81 (0.017), $1.80(0.017)$ \\
\hline \multirow[t]{2}{*}{ ADRB1 } & 229309_at & $\begin{array}{l}3.59(0.034), 1.81(0.387), 1.91(0.355), 2.07(0.411), 2.65(0.162), 2.57(0.000) \text {, } \\
1.75(0.000)\end{array}$ \\
\hline & 229277_at & $1.79(0.339), 1.64(0.425)$ \\
\hline \multirow{2}{*}{ AGTR1 } & 205357_s_at & $1.70(0.481), 1.54(0.108), 2.51(0.000), 1.75(0.001)$ \\
\hline & 208016_s_at & $1.50(0.112), 1.77(0.039), 2.04(0.272)$ \\
\hline C3AR1 & 209906_at & 1.55 (0.627), $1.80(0.000), 2.03(0.000), 1.77(0.000)$ \\
\hline \multirow{2}{*}{ CELSR3 $^{\text {a) }}$} & 40020_at & $5.09(0.011), 1.56(0.408), 1.53(0.485), 1.59$ (0.034) \\
\hline & 205165_at & $4.72(0.012)$ \\
\hline \multirow{6}{*}{ CHRM3 } & 1553705_a_at & $\begin{array}{l}3.04(0.027), 1.53(0.061), 1.83(0.260), 4.26(0.045), 1.59(0.048), 2.67(0.000) \text {, } \\
2.08(0.077), 1.81(0.000), 1.68(0.000)\end{array}$ \\
\hline & 214596_at & $\begin{array}{l}4.89(0.018), 1.76(0.113), 1.97(0.407), 6.75(0.037), 1.94(0.036), 3.51(0.000) \text {, } \\
3.30(0.020), 3.42(0.002), 3.96(0.002)\end{array}$ \\
\hline & 242488_at & $\begin{array}{l}6.32(0.020), 1.69(0.176), 1.71(0.593), 8.25(0.038), 2.13(0.039), 5.21(0.002), \\
3.16(0.002), 3.27(0.002)\end{array}$ \\
\hline & 1559633_a_at & $4.11(0.047), 1.52(0.650), 4.45(0.135), 2.08$ (0.003), $2.89(0.000), 2.53(0.000)$ \\
\hline & 1564339_a_at & $2.71(0.023), 1.83(0.000), 1.72(0.000)$ \\
\hline & 1559634_at & $1.66(0.128), 1.67(0.000), 1.57(0.007)$ \\
\hline \multirow{3}{*}{$\mathrm{CXCR}^{\mathrm{a})}$} & 211919_s_at & $2.45(0.220), 6.63(0.000), 8.52(0.000), 6.06(0.000)$ \\
\hline & 209201_x_at & $2.56(0.194), 6.46(0.000), 8.34(0.000), 6.06(0.000)$ \\
\hline & 217028_at & $2.95(0.195), 2.53(0.000), 2.47(0.000), 2.29(0.000)$ \\
\hline F2R & 203989_x_at & $\begin{array}{l}1.55(0.150), 1.58(0.023), 1.54(0.667), 1.60(0.145), 1.87(0.000), 1.66(0.002) \text {, } \\
1.76(0.002)\end{array}$ \\
\hline \multirow{2}{*}{ F2RL1 $1^{\text {a) }}$} & 213506_at & 3.30 (0.039), $2.02(0.149), 2.95(0.507), 1.90(0.001), 1.90(0.000)$ \\
\hline & 206429_at & $1.88(0.024), 2.20(0.000), 2.10(0.000)$ \\
\hline F2RL2 ${ }^{\text {a) }}$ & 230147_at & $2.58(0.653), 2.21(0.166), 1.98(0.304), 1.67(0.013), 2.30(0.000)$ \\
\hline FPR1 & 205119_s_at & $1.64(0.002), 3.22(0.000), 3.31(0.000), 2.10(0.000)$ \\
\hline \multirow{2}{*}{ FPR3 $3^{a)}$} & 214560_at & $1.67(0.002), 1.54(0.292)$ \\
\hline & 230422_at & $2.44(0.340), 2.05(0.000), 2.33(0.000), 2.16(0.000)$ \\
\hline GPR183 & 205419_at & $1.52(0.351), 3.41(0.000), 3.65(0.000), 2.42(0.000)$ \\
\hline GRPR $^{\text {a) }}$ & 207929_at & 1.89 (0.189), 1.60 (0.002), $2.18(0.000), 1.69(0.006)$ \\
\hline OR51E1 & 229768_at & $13.30(0.012), 2.64(0.441), 3.22(0.259), 2.19(0.535), 2.82(0.842)$ \\
\hline \multirow{3}{*}{ OR51E2 } & 221424_s_at & $\begin{array}{l}14.38(0.003), 3.96(0.037), 4.66(0.321), 4.55(0.284), 5.44(0.000), 6.08(0.000) \text {, } \\
1.51(0.203), 4.86(0.006), 2.33(0.006)\end{array}$ \\
\hline & 232482_at & $\begin{array}{l}29.45(0.001), 6.80(0.072), 2.38(0.178), 4.18(0.290), 3.92(0.271), 4.33(0.000) \text {, } \\
4.92(0.000), 1.88(0.279), 3.38(0.094), 4.15(0.001), 2.57(0.001)\end{array}$ \\
\hline & 236121_at & $\begin{array}{l}36.83(0.003), 6.10(0.236), 24.45(0.171), 2.98(0.406), 3.50(0.329), 2.28(0.006) \text {, } \\
2.43(0.001), 5.04(0.207), 8.96(0.083), 3.57(0.022), 1.74(0.022)\end{array}$ \\
\hline \multirow{2}{*}{ SSTR1 } & 235591_at & $2.18(0.325), 2.32(0.150), 2.54(0.000), 1.83(0.071)$ \\
\hline & 208482_at & $1.75(0.000)$ \\
\hline
\end{tabular}

a) Overexpressed in $\mathrm{PCa}$ and $\mathrm{BrCa}$. 
Table 3: Overexpression of G-proteins in breast cancer tissue (min $4 \times>1.5$ fold induction)

\begin{tabular}{|c|c|c|}
\hline Gene & Probe ID & Fold increase ( $p$-Value) \\
\hline \multirow{2}{*}{ ADGRV1 } & 223582_at & $2.02(0.063), 2.04(0.297), 2.29(0.021), 1.59(0.106), 1.53(0.276), 1.62(0.000)$ \\
\hline & 224275_at & $1.55(0.024)$ \\
\hline ADORA3 & 206171_at & $1.89(0.062), 2.20(0.010), 2.75(0.000), 2.23(0.032)$ \\
\hline \multirow{2}{*}{ CCR1 } & 205098_at & $1.97(0.090), 1.92(0.105), 1.61(0.136), 1.68(0.265)$ \\
\hline & 205099_s_at & $1.80(0.026)$ \\
\hline CCR2 & 206978_at & $1.56(0.228), 1.65(0.729), 1.65(0.181), 2.03(0.051)$ \\
\hline CCR5 & 206991_s_at & $\begin{array}{l}1.74(0.011), 2.69(0.359), 2.80(0.001), 2.08(0.003), 1.90(0.030), 1.69(0.000), 1.88 \\
(0.002)\end{array}$ \\
\hline CCR7 & 206337_at & $2.80(0.242), 3.68(0.638), 1.86(0.249), 1.58(0.001), 2.52(0.024)$ \\
\hline CELSR1 & 41660_at & $5.79(0.003), 3.37(0.122), 2.56(0.014), 4.21(0.000), 4.51(0.001), 5.93(0.000)$ \\
\hline \multirow{2}{*}{ CELSR2 } & 36499_at & $6.02(0.000), 5.31(0.047), 1.80(0.130), 2.48(0.080), 2.78(0.000)$ \\
\hline & 204029_at & $4.15(0.001), 4.33(0.076), 1.68(0.135), 2.51(0.066), 2.14(0.000)$ \\
\hline CELSR3 & 40020_at & $2.36(0.006), 1.54(0.071), 1.98(0.000), 1.55(0.085), 1.73(0.000), 1.81(0.000)$ \\
\hline CXCR3 & 207681_at & $1.94(0.548), 1.66(0.024), 1.56(0.025), 1.63(0.000)$ \\
\hline \multirow{3}{*}{ CXCR4 } & 211919_s_at & $\begin{array}{l}2.67(0.017), 2.68(0.061), 4.60(0.525), 2.14(0.047), 3.29(0.000), 2.45(0.006), 1.60 \\
(0.002), 2.96(0.000)\end{array}$ \\
\hline & 209201_x_at & $\begin{array}{l}2.66(0.016), 2.54(0.087), 4.54(0.480), 2.69(0.013), 3.85(0.000), 2.94(0.002), 1.62 \\
(0.002), 2.62(0.000)\end{array}$ \\
\hline & 217028_at & $\begin{array}{l}2.51(0.036), 3.18(0.004), 2.89(0.664), 2.47(0.011), 2.27(0.006), 2.10(0.043), 2.79 \\
(0.000), 1.83(0.032)\end{array}$ \\
\hline F2RL1 & 213506_at & $2.06(0.267), 1.81(0.643), 2.52(0.033), 3.31(0.000), 3.92(0.009), 2.42(0.000)$ \\
\hline F2RL2 & 230147_at & $1.54(0.573), 4.43$ (0.662), $3.60(0.048), 3.87(0.008), 8.53(0.000), 3.22(0.000)$ \\
\hline \multirow{2}{*}{ FPR3 } & 214560_at & $2.05(0.043), 1.69(0.002), 2.22(0.000), 1.80(0.032), 2.17(0.000)$ \\
\hline & 230422_at & 1.77 (0.259), 1.63 (0.194), 1.70 (0.260), 3.58 (0.002) \\
\hline GPR171 & 207651_at & $2.23(0.245), 5.04(0.503), 1.91(0.220), 1.59(0.402)$ \\
\hline GPR18 & 210279 at & $2.51(0.405), 1.60(0.066), 1.89(0.052), 1.95(0.006)$ \\
\hline GPR19 & 207183_at & $1.68(0.012), 1.56(0.057), 1.58(0.003), 1.72(0.023), 2.28(0.000)$ \\
\hline GPR37 & 209631_s_at & $2.77(0.022), 1.96(0.097), 2.29(0.034), 1.71(0.000)$ \\
\hline \multirow{2}{*}{ GPR39 } & 229105_at & $1.70(0.135), 3.35(0.011), 1.86(0.081), 2.04(0.152), 2.67(0.000)$ \\
\hline & 229104_s_at & $1.73(0.030)$ \\
\hline GPR65 & 214467_at & 1.95 (0.109), $1.60(0.032), 1.76(0.041), 1.55(0.014)$ \\
\hline GPR68 & 229055_at & $\begin{array}{l}2.31(0.009), 1.79(0.031), 1.79(0.241), 2.20(0.000), 2.13(0.000), 1.90(0.012), 1.82 \\
(0.000), 1.63(0.000)\end{array}$ \\
\hline GPR84 & 223767_at & $1.80(0.102), 1.55(0.015), 1.70(0.057), 1.70(0.000), 1.90(0.015), 2.66(0.000)$ \\
\hline \multirow{2}{*}{ GPRC5A } & 203108_at & $2.33(0.175), 3.90(0.013), 5.26(0.000), 4.35(0.015), 5.52(0.000), 4.31(0.000)$ \\
\hline & 212444_at & $4.09(0.005), 8.21(0.000), 3.73(0.019), 3.38(0.000), 2.13(0.013)$ \\
\hline GRPR & 207929_at & $1.78(0.003), 1.66(0.143), 1.66(0.001), 1.61(0.035)$ \\
\hline KISS1R & 242517_at & $2.47(0.103), 1.82(0.196), 4.46(0.039), 2.58(0.000), 1.65(0.181)$ \\
\hline LPAR2 & 206723_s_at & $2.48(0.008), 1.72(0.199), 1.67(0.184), 1.55(0.086), 2.28(0.000)$ \\
\hline LPAR5 & 230252_at & $2.00(0.565), 1.82(0.003), 1.79(0.000), 1.90(0.001)$ \\
\hline \multirow{2}{*}{ OPN3 } & 224392_s_at & $2.77(0.006), 1.92(0.037), 2.16(0.041), 1.55(0.000)$ \\
\hline & 219032_x_at & $1.20(0.212), 1.68(0.059), 1.95(0.151), 1.74(0.000), 1.55(0.000)$ \\
\hline P2RY2 & 206277_at & $1.82(0.030), 1.56(0.025), 1.91(0.000), 1.80(0.004), 1.68(0.005)$ \\
\hline
\end{tabular}




\begin{tabular}{lll} 
& 236280_at & $\begin{array}{l}1.57(0.396), 3.49(0.563), 3.50(0.006), 2.83(0.003), 2.71(0.012), 1.59(0.005), 1.77 \\
(0.021)\end{array}$ \\
P2RY10 & 1553856_s_at & $1.94(0.031), 1.66(0.036), 1.68(0.000)$ \\
& 214615_at & $1.55(0.064), 1.58(0.005), 1.55(0.000)$ \\
S1PR3 & 228176_at & $2.20(0.016), 2.42(0.000), 2.02(0.042), 1.72(0.007)$ \\
\hline
\end{tabular}

Table 4: Final selection of receptors for future targeting of cancer cells

\begin{tabular}{lcc}
\hline Receptor & Ligand & Current role in cancer treatment \\
\hline Prostate cancer & Angiotensin II & \\
\hline AGTR1 & Thrombin activated & Anti angiogenic, PCa clinical pilot study [54-56] \\
F2R & N-formyl peptides & None \\
FPR1 & CCL19, 21 & None \\
\hline Breast cancer & CXCL9, 10, 11 & None \\
CCR7 & N-arachidonyl glycine & None, recently de-orphaned \\
CXCR3 & Adropin & None, recently de-orphaned \\
GPR18 & Prosaptide & None, recently de-orphaned \\
GPR19 & BigLEN & None, recently de-orphaned \\
GPR37 & Kisspeptin & None \\
GPR171 & & \\
KISS1R & Thrombin activated & None \\
\hline Prostate and breast cancer & GRP & PCa and others, diagnosis, radio and chemotherapy [54, 57] \\
\hline F2RL2 & & \\
GRPR & &
\end{tabular}

would represent a challenge to link with nanoparticles while maintaining activity on the receptor. Therefore we did not follow this group further. Two olfactory receptors were identified in PCa with OR51E2 very strongly and frequently expressed. However, this type of receptor is unlikely to be useful for the active targeting of nanoparticles due to the fact that in most cases the detected ligands are not known or are small molecules. In this case targeting may be considered with specific antibodies. However, this is beyond the scope of the current report and is not further discussed. Orphan receptors can be of future interest once the native ligands have been discovered. Our investigations revealed one adhesion (ADGRV1) and three cadherin type (CelsR1-3) orphan GPCRs (two in PCa and $\mathrm{BrCa}$, and two in $\mathrm{BrCa}$ only). Of particular interest are the CelsR1-3 receptors which have shown very frequent and strong expression. In addition to this the orphan receptor GPRC5A showed very high and frequent expression in $\mathrm{BrCa}$ and GPR183 was moderately expressed in some $\mathrm{PCa}$ tissue. The future potential of orphan receptors is exemplified in this study by several recently de-orphaned members which have been identified as part of this project (e.g. GPR18, 19, 37 and 171) [25-28]. GPR65 is an additional recently de-orphaned, $\mathrm{pH}$ sensitive receptor and was deemed as too challenging for chemical conjugation purposes [29]. However, in the following sections the focus is on peptide and lipid receptors as these types show the highest potential for active targeting purposes in the near future. A summary of the identified receptors with peptide and lipid ligands is shown in Table 4.

\section{GPCRs with peptide ligands}

Of all overexpressed GPCRs, $45 \%$ were peptidic receptors, five specific to $\mathrm{PCa}$, nine specific to $\mathrm{BrCa}$ and five overexpressed in $\mathrm{PCa}$ and $\mathrm{BrCa}$. The latter group contained the GRP receptor previously reported to be frequently overexpressed in prostate and breast cancer tissue [30]. Our data selection algorithm also identified the somatostatin receptor SSTR1 in PCa tissue. A peptidic somatostatin receptor ligand (octreotide) has been reportedly coupled with lutetium-177 and tested in phase 2 trials for the radio treatment of neuroendocrine tumors [31]. These results clearly validate the presented approach. 
The next step was to select the most promising receptors for effective and safe cancer cell targeting. This is most likely achieved using receptors with low expression in healthy tissue and high expression in neoplastic tissue. The information for receptor expression in healthy tissues was collected from the Human Protein Atlas (HPA) and is shown in Supplementary Data 1 with RNAseq data given for each receptor in the right column, and protein levels are indicated in the left hand column for each receptor, with 0 (not detected), 1 (low), 2 (medium) and 3 (high protein expression). From all selected receptors which were identified as overexpressed in PCa cells, we judged AGTR1 as most favorable as expression in healthy individuals was detected in only three tissue types, followed by FPR1 and F2R which showed expression in 15 out of 45 tissues. FPR 1 showed expression at low levels only, with the exception of bone marrow. Similarly, the same kind of analysis of receptors with overexpression in BrCa cells revealed CCR7, CXCR3, GPR171 and GPR37 to be of most interest as they were only expressed in very few tissues of healthy individuals. A total of five receptors were identified in $\mathrm{PCa} \& \mathrm{BrCa}$ and protein expression data were only available for F2RL1 which was deemed unsuitable due to ubiquitous expression in most tissues. It has been well documented that protein and mRNA expression do not always correlate. Nevertheless, in the absence of information for protein expression we assessed mRNA expression and noted very limited expression of GRPR and KISS1R in almost all tissues. These receptors might be most suitable for selective and active targeting of cancer cells. To a lesser extent GPR19 and F2RL2 might also be considered.

\section{Bioactive lipid receptors}

Interestingly, overexpressed lipid receptors were only detected in breast cancer tissue. The recently deorphaned GPR18 showed medium protein expression in spleen, lymph node and tonsil (Supplementary Data 1). This was further confirmed by RNAseq which was limited to immune tissue (Supplementary Data 1). All other lipid receptors showed ubiquitous expression in most tissues and were therefore considered potentially problematic for selective targeting of cancer cells.

Many GPCRs have been reported to affect cancer relevant mechanisms. Surprisingly, only very few drugs have been launched to modulate these receptors for the purpose of cancer treatment [32], and to date even fewer receptors have been used for active targeting. A summary of all receptors selected from this study as potential cancer cell targeting options are summarized in Table 4.

\section{Ligand docking}

A ligand can only guide drug carriers to target cells if the bound ligand protrudes from the receptor in a way that displays functional groups amenable for chemical conjugation. Docking experiments were conducted with selected ligands to gain structural insight into the receptor binding modalities of FPR1, KISS1R, GRPR and GPR18. In a first step, the Swiss-Model Server [33-35] was used to build homology based receptor models. The target sequences (see Supplementary Data 2) were submitted to the server and the automated mode was used to identify 333, 342, 327 and 279 structural templates for FPR1, KISS1R, GRPR and GPR18, respectively.

In a second step, the templates with the highest global quality estimation scores (GMQE) [35] were selected for modelling and the quality of the structures were ranked using the QMEAN scoring function [34]. The highest scoring models were taken forward for docking experiments. The public CABS-dock server [36] was used for docking studies with the peptide ligands uPAR88-92, kisspeptin14 and neuromedin C against the cognate receptors FPR1, KISS1R and GRPR, respectively (Figure 5A-5C). The SwissDock server [37, 38] was used for docking of the endogenous lipid ligand N-Arachidonylglycine (NAGly) [26] against GPR18 (Figure 5D).

Peptide ligands offer the possibility to produce fusion proteins with ELPs or other self-assembling proteins. Proof of concept for this has already been provided in our earlier work, when the N-terminal amino acid of GRP (neuromedin C) was successfully fused to ELP micelles and increased uptake into prostate cancer cells demonstrated [22]. Even though GRP appeared to be buried within the binding site $(5 \mathrm{C})$ it was possible to use the N-terminal amino acid for conjugation while maintaining full ligand activity. Potentially, the uPAR88-92 (SRSRY) pentapeptide [39] (Figure 5A) may behave similarly when linked to nanoparticles via the $\mathrm{N}$-terminal amino group, although this hypothesis remains subject to experimental testing. In contrast, the slightly larger kisspeptin14 (5B) seems very well suited for chemical linkage to nanocarriers via the C-terminal amino acid fully exposed on the receptor surface. The model for GPR18 suggests the attachment of a relatively polar linker to the $\mathrm{C} 20$ carbon to bridge the linkage to potential binding groups on nanoparticles.

\section{DISCUSSION}

The sheer amount of gene expression data generated using most modern technologies makes it difficult for a single laboratory to exploit all of the information generated. Collection of data from multiple datasets within repositories allows for data retrieval and combination, potentially reaching higher statistical significance with meta studies designed for specific biological questions. We have outlined a process to systematically identify overexpressed GPCRs in cancer tissue.

GPCRs have been recognized as emerging cancer therapeutic target molecules. Several studies show the 
involvement of GPCR activity in cancer development [32]. They regulate a broad range of cellular signal transduction processes and can be of paramount importance for tumor initiation and progression. Thus, it comes of no surprise that several successful anti-cancer drugs target GPCRs, such as Plerixafor targeting the CXCR4 gene product. However, in contrast to most oncogenes, it is not only gene mutations which drive the GPCR's tumorigenic capacity. Overexpression of GPCRs or excess ligand production can induce oncogenic transformation. As such, overexpressed GPCRs may not only serve as direct targets for anti-cancer drugs but can be harnessed to guide anti-cancer drugs to cancer cells. Receptor-bound drug carrying ligands will be internalized through endocytosis and the drug released e.g. by the acidic environment within endosomes. However, depending on the drug, internalization may not be necessary. For example, some drug carriers might be immobilized on the cellular surface and deliver the anti-
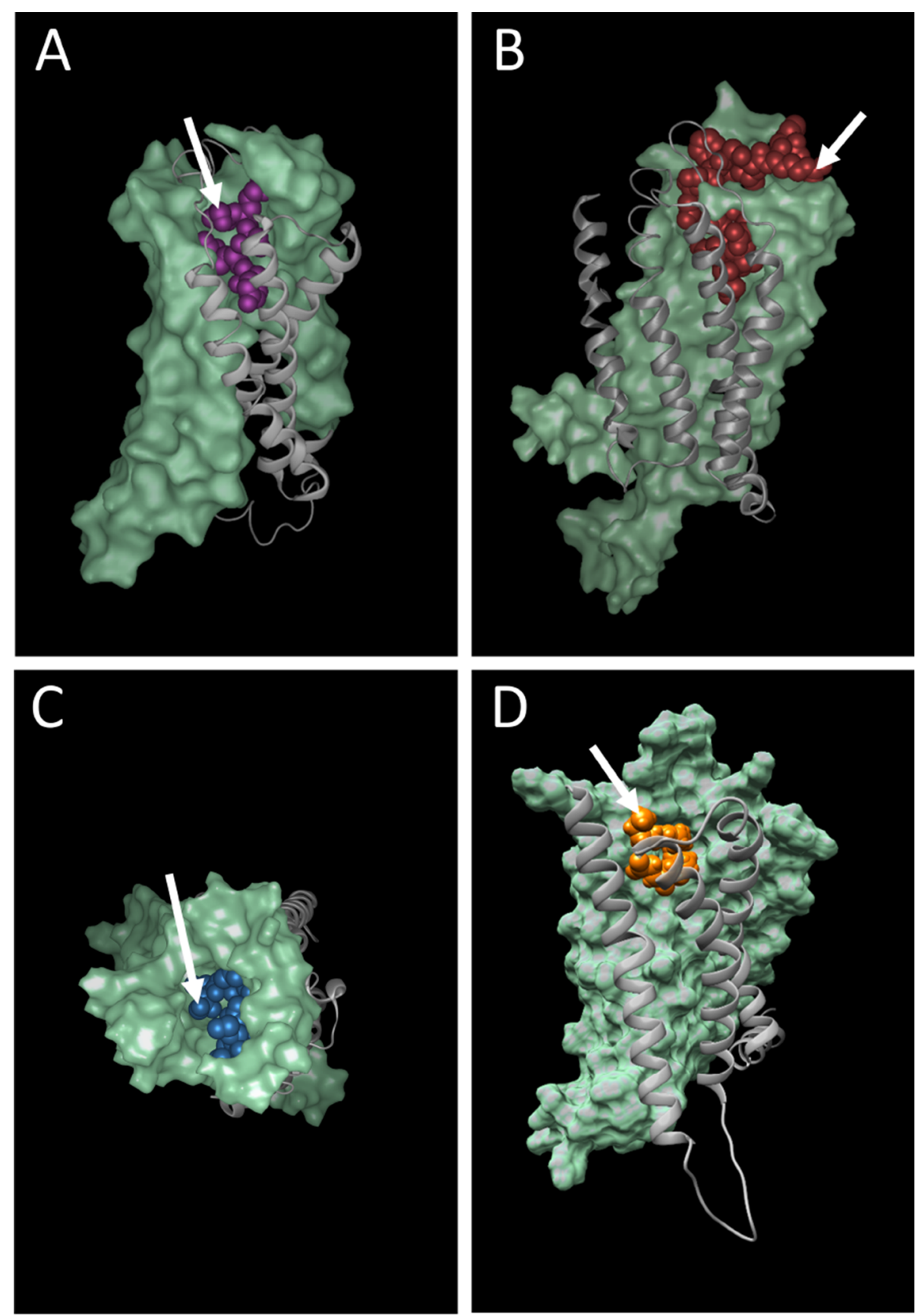

Figure 5: Docking of peptide and lipid ligands into their cognate receptors (A) FPR1, (B) KISS1R, (C) GRPR and (D) GPR18. Arrows depict putative anti-cancer agent attachment sites on the N-terminal amino group of uPAR88-92 (A) and neuromedin C (C); the C-terminal carboxy group of kisspeptin14 (B); the $\mathrm{C} 20$ atom of arachidonic acid in N-Arachidonylglycine (D). 
cancer compounds into the acidic tumor environment, or in a radiation based therapy, a drug only needs to reach the surface of a cancer cell by active targeting to perform its action.

Here, we showed the application of a meta study of gene expression data for the identification of overexpressed GPCRs in prostate cancer and breast cancer tumor cells. The rationale that GPCR receptor ligands coupled to an anti-cancer compound or nanocarrier would specifically target and combat cancer cells may pave the way for more effective therapeutics.

The basis for the presented approach lies (1) in the organized collection of data from public sources and (2) in the strength of computer programs to select and order the data according to one's requirements. As data acquired in various laboratories using different protocols may vary considerably due to many uncontrollable influences inherent of biological samples, we defined quantitative and qualitative threshold levels to account for these variations and to therefore strengthen the significance of the data. For example, only data sets also including control samples measuring gene expression in healthy tissue have been taken into account. Furthermore, signal transduction molecules such as GPCRs are expressed below average (Figures 3B and 4B). Specifically, the mean expression of all genes was calculated to be approximately $5.5(\log 2$ expression), whilst the average of all GPCRs was lower by about 2 fold (ca. $4.5 \log 2$ expression). Comparison of the maxima revealed an approximate expression difference of 16 fold ( $\log 2$ of 14 vs 10). Cellular GPCR expression levels must be maintained relatively low for most of the time. In this way, cells can react quickly to agonists for downstream signal transduction. Subtle perturbations in their expression levels may therefore be a significant sign of altered cell state such as occurs when a healthy cell turns into a tumor cell. We reasoned that a $50 \%$ increase in expression of GPCRs in cancer cells relative to healthy cells is a sign for this kind of switch of a cellular state. To account for this relatively low cutoff level, only GPCR genes overexpressed in at least 4 patient sample groups were selected for further consideration. We noted that increasing the cutoff level for overexpression to a factor of 2 would lead to approximately the same number of GPCR genes in the final pool although the initial number of overexpressed GPCR genes would have dropped substantially from 186 to $70 . P$-values were calculated to assess differential expression of each GPCR gene when cancer tissue was compared to normal tissue. The $p$-values ranged from $<0.0005$ to 0.958 with about $70 \%$ of the values being $<0.1$. Whilst high values indicate differences of lower significance between the samples, they also reflect the very strong heterogeneity that often occurs between cancer samples. Under these circumstances, large $p$-values will be likely obtained with small sample groups as indicated in Table 1. In fact, the statistical analysis performed here has to be interpreted with regard to such heterogeneity. The selection of the GPCR genes is based on data of a population of cancer samples and serves to narrow down possible candidates for targeted treatment. While some of the selected GPCRs may function as a target in most cancer patients, others may only be overexpressed in $30 \%$ or less of all cancer tissues. However, in the context of personalized cancer treatment, the consideration of these less frequently overexpressed receptors are of high practical value. Our findings need to be confirmed through experimental testing. Finally, when anti-cancer drugs are actively targeted to GPCRs on cancer cells, it is of advantage to choose receptors with a general low expression in healthy tissues, as this will minimize possible side effects.

Two groups of overexpressed GPCRs can be expected when following the described selection procedure (Figure 2). (1) GPCRs that have been described to have a functional role in cancer initiation and progression and (2) GPCRs with no known causal connection to the tumorigenic state of a cell. Members of both groups are well suited for the purpose of serving as a cellular lighthouse to guide anti-cancer drug-loaded receptor ligands to the tumor cells.

Based on the present knowledge, we have selected GPCRs from both groups. For example, the Gastrin Releasing Peptide Receptor (GRPR) is overexpressed in various cancer type cells and was suggested to play a significant role in metastasis. Also, the KISS1 receptor was recently shown to promote breast cancer due to overexpression [40]. The selection of these two examples as well as others (Table 4) indicate the validity of our algorithm. On the other hand, an involvement of FPR1, GPR18 and others (Table 4) in cancer promotion has not been described. All of the finally selected GPCR genes have either peptidic or lipidic ligands that can be relatively easily conjugated to drug nanocarriers or directly to anti-cancer small molecule drugs. In fact, it has been recently shown that GRPR on prostate cancer cells can be targeted with hybrid elastin-like polypeptide/liposome nanoparticles via a GRP-ELP fusion protein [23].

Our approach has some limitations. We are aware that these kind of expression studies may miss potentially overexpressed GPCRs whose mRNA expression levels stay below our arbitrary selection criteria of factor 1.5. On the other hand, enhanced mRNA expression may not necessarily lead to enhanced protein levels. Protein measurements are needed to confirm our data before designing targeted therapeutics. The systematic attachment of therapeutic molecules to ligands for overexpressed GPCRs would pave the way to personalized therapeutics in cancer. Patients can easily be tested for overexpression and ligand binding ability of the candidate GPCRs and treated accordingly. Whether or not the GPCR systems used for this kind of therapeutic approach may also be used as a cancer diagnostic or even cancer prognostic tool is another interesting aspect to address in future work. 


\section{METHODS}

\section{Data set search strategy}

The NCBI GEO database was systematically searched to identify Entrez GEO DataSets with micro array expression data relevant for prostate and breast cancer. The search was focused on the GPL570 platform (single channel array) which represented $>90 \%$ of all non-olfactory GPCR genes and with $>120,000$ available samples provided sufficient data. Only studies with information from primary cancer tissue were considered in our analysis. Hence, experiments with in vivo cell lines and xenograft models were excluded. Furthermore, studies without control samples (e.g. healthy tissue) or studies with $<10$ samples were not considered. Finally 6 data sets were selected for prostate cancer and 5 for breast cancer (Table 1).

\section{Search for overexpressed GPCR genes}

The CEL files of all datasets listed in Table 1 were retrieved from the NCBI GEO archive. The ArrayStar software (DNAStar Inc, Madison, WI, USA) was used to normalize the data with the robust multi-array average (RMA) method [24] to assure consistent handling of all data sets. Affymetrix annotation files were used to retrieve gene specific expression data with official gene symbols. The $7 \mathrm{tm}$ and GPCR Protein Family (Pfam) domains were used to identify all GPCRs listed in the Ensemble database (ensemble.org) and 755 GPCR genes were compiled including orphan, taste, olfactory and vomeronasal receptors. A subset of 437 receptors were represented by at least 1 DNA probe on the GPL570 platform.

\section{Statistical analysis}

Patient samples from different studies were stratified into groups of distinct subtypes and fold expression was calculated between cancer tissues and the corresponding normal tissues. An unpaired, two-tailed, equal variance Student's $t$-Test was applied to assess the significance of differentially expressed GPCR genes.

\section{Homology modeling and docking}

Receptor protein sequences were submitted to the Swiss-Model Server [33-35] and suitable templates were automatically searched in the SWISS-MODEL template library (SMTL, version 2017-10-23, last included PDB release 2017-10-13) using the Blast [41] and HHBlits [42] methods in parallel. The templates with the highest quality according to the global quality estimation score (GMQE) have then been selected for model building. Models were built based on the target-template alignment using ProMod3 and the global and per-residue model qualities were assessed using the QMEAN scoring function [34].
Finally, the CABS-dock server [36] was used for docking studies with selected peptide ligands against receptor models. The SwissDock server [37, 38] was used for docking of lipid ligands. Various docking results were clustered according to the binding site and modality on the receptor. Visual checks of the structures were performed to discard clusters which showed binding in unexpected sites. Top ranked dockings from the finally prioritized clusters were rendered with Protean 3D (DNAStar Inc.) or Chimera (UCSF), and the structures were used to assess potential chemical conjugation for receptor targeting.

\section{Abbreviations}

BrCa: breast cancer; ELP: elastin-like polypeptide; EPR: enhanced permeability and retention effect; GEO: gene expression omnibus; GMQE: global quality estimation scores; GPCR: G-protein-coupled receptor; GRP: gastrin-releasing peptide; GRPR: gastrin-releasing peptide receptor; HPA: Human Protein Atlas; IDC: invasive ductal carcinoma; NAGly: N-arachidonylglycine; PCa: prostate cancer; RMA: robust multi-array.

\section{Author contributions}

Both authors contributed equally on all aspects of this work.

\section{ACKNOWLEDGMENTS}

Computational resources from the VITAL-IT project (Swiss Institute of Bioinformatics, Lausanne, Switzerland) were used for part of this work. Some of the molecular graphics images were produced using the UCSF Chimera package from the Resource for Biocomputing, Visualization and Informatics at the University of California, San Francisco. We thank Dr Eric Ma for advice with the DNAStar software packages and Dr Katrina Erny for critical review of the manuscript.

\section{CONFLICTS OF INTEREST}

The authors report no conflicts of interest in this work.

\section{FUNDING}

This study was supported by UniSA and FHNW research funding.

\section{REFERENCES}

1. Wicki A, Witzigmann D, Balasubramanian V, Huwyler J. Nanomedicine in cancer therapy: challenges, opportunities, and clinical applications. J Control Release. 2015; 200:138-57. 
2. Hobbs SK, Monsky WL, Yuan F, Roberts WG, Griffith L, Torchilin VP, Jain RK. Regulation of transport pathways in tumor vessels: role of tumor type and microenvironment. Proc Natl Acad Sci U S A. 1998; 95:4607-12.

3. Gaumet M, Vargas A, Gurny R, Delie F. Nanoparticles for drug delivery: the need for precision in reporting particle size parameters. Eur J Pharm Biopharm. 2008; 69:1-9.

4. Barragan F, Carrion-Salip D, Gomez-Pinto I, GonzalezCanto A, Sadler PJ, de Llorens R, Moreno V, Gonzalez C, Massaguer A, Marchan V. Somatostatin subtype-2 receptortargeted metal-based anticancer complexes. Bioconjug Chem. 2012; 23:1838-55.

5. de Jong M, Breeman WA, Kwekkeboom DJ, Valkema R, Krenning EP. Tumor imaging and therapy using radiolabeled somatostatin analogues. Acc Chem Res. 2009; 42:873-80.

6. Okarvi SM. Peptide-based radiopharmaceuticals and cytotoxic conjugates: potential tools against cancer. Cancer Treat Rev. 2008; 34:13-26.

7. Accardo A, Morisco A, Tesauro D, Pedone C, Morelli G. Naposomes: a new class of peptide-derivatized, targetselective multimodal nanoparticles for imaging and therapeutic applications. Ther Deliv. 2011; 2:235-57.

8. Aloj L, Aurilio M, Rinaldi V, D'Ambrosio L, Tesauro D, Peitl PK, Maina T, Mansi R, von Guggenberg E, Joosten L, Sosabowski JK, Breeman WA, De Blois E, et al. Comparison of the binding and internalization properties of 12 DOTA-coupled and (1)(1)(1)In-labelled CCK2/gastrin receptor binding peptides: a collaborative project under COST Action BM0607. Eur J Nucl Med Mol Imaging. 2011; 38:1417-25.

9. Accardo A, Mansi R, Morisco A, Mangiapia G, Paduano L, Tesauro D, Radulescu A, Aurilio M, Aloj L, Arra C, Morelli G. Peptide modified nanocarriers for selective targeting of bombesin receptors. Mol Biosyst. 2010; 6:878-87.

10. Parry JJ, Kelly TS, Andrews R, Rogers BE. In vitro and in vivo evaluation of 64Cu-labeled DOTA-linkerbombesin(7-14) analogues containing different amino acid linker moieties. Bioconjug Chem. 2007; 18:1110-7.

11. Smith CJ, Volkert WA, Hoffman TJ. Radiolabeled peptide conjugates for targeting of the bombesin receptor superfamily subtypes. Nucl Med Biol. 2005; 32:733-40.

12. He Y, Zhang L, Song C. Luteinizing hormone-releasing hormone receptor-mediated delivery of mitoxantrone using LHRH analogs modified with PEGylated liposomes. Int J Nanomedicine. 2010; 5:697-705.

13. Nagy A, Schally AV. Targeting of cytotoxic luteinizing hormone-releasing hormone analogs to breast, ovarian, endometrial, and prostate cancers. Biol Reprod. 2005; 73:851-9.

14. Falciani C, Brunetti J, Lelli B, Accardo A, Tesauro D, Morelli G, Bracci L. Nanoparticles exposing neurotensin tumor-specific drivers. J Pept Sci. 2013; 19:198-204.
15. Falciani C, Fabbrini M, Pini A, Lozzi L, Lelli B, Pileri S, Brunetti J, Bindi S, Scali S, Bracci L. Synthesis and biological activity of stable branched neurotensin peptides for tumor targeting. Mol Cancer Ther. 2007; 6:2441-8.

16. Muggia FM, Hainsworth JD, Jeffers S, Miller P, Groshen S, Tan M, Roman L, Uziely B, Muderspach L, Garcia A, Burnett A, Greco FA, Morrow CP, et al. Phase II study of liposomal doxorubicin in refractory ovarian cancer: antitumor activity and toxicity modification by liposomal encapsulation. J Clin Oncol. 1997; 15:987-93.

17. Bulbake U, Doppalapudi S, Kommineni N, Khan W. Liposomal Formulations in Clinical Use: An Updated Review. Pharmaceutics. 2017; 9.

18. Desai N, Trieu V, Yao Z, Louie L, Ci S, Yang A, Tao C, De T, Beals B, Dykes D, Noker P, Yao R, Labao E, et al. Increased antitumor activity, intratumor paclitaxel concentrations, and endothelial cell transport of cremophorfree, albumin-bound paclitaxel, ABI-007, compared with cremophor-based paclitaxel. Clin Cancer Res. 2006; 12:1317-24.

19. Lee KS, Chung HC, Im SA, Park YH, Kim CS, Kim SB, Rha SY, Lee MY, Ro J. Multicenter phase II trial of Genexol-PM, a Cremophor-free, polymeric micelle formulation of paclitaxel, in patients with metastatic breast cancer. Breast Cancer Res Treat. 2008; 108:241-50.

20. Kataoka K, Harada A, Nagasaki Y. Block copolymer micelles for drug delivery: design, characterization and biological significance. Adv Drug Deliv Rev. 2001; 47:113-31.

21. Sun G, Hsueh PY, Janib SM, Hamm-Alvarez S, MacKay JA. Design and cellular internalization of genetically engineered polypeptide nanoparticles displaying adenovirus knob domain. J Control Release. 2011; 155:218-26.

22. Zhang W, Garg S, Eldi P, Zhou FH, Johnson IR, Brooks DA, Lam F, Rychkov G, Hayball J, Albrecht H. Targeting prostate cancer cells with genetically engineered polypeptide-based micelles displaying gastrin-releasing peptide. Int J Pharm. 2016; 513:270-279.

23. Zhang W, Song Y, Eldi P, Guo X, Hayball JD, Garg S, Albrecht H. Targeting prostate cancer cells with hybrid elastin-like polypeptide/liposome nanoparticles. Int J Nanomedicine. 2018; 13:293-305.

24. Irizarry RA, Hobbs B, Collin F, Beazer-Barclay YD, Antonellis KJ, Scherf U, Speed TP. Exploration, normalization, and summaries of high density oligonucleotide array probe level data. Biostatistics. 2003; 4:249-64.

25. Gomes I, Aryal DK, Wardman JH, Gupta A, Gagnidze K, Rodriguiz RM, Kumar S, Wetsel WC, Pintar JE, Fricker LD, Devi LA. GPR171 is a hypothalamic G protein-coupled receptor for BigLEN, a neuropeptide involved in feeding. Proc Natl Acad Sci U S A. 2013; 110:16211-6.

26. McHugh D, Page J, Dunn E, Bradshaw HB. Delta(9) -Tetrahydrocannabinol and $\mathrm{N}$-arachidonyl glycine are full agonists at GPR18 receptors and induce migration in 
human endometrial HEC-1B cells. Br J Pharmacol. 2012; 165:2414-24.

27. Meyer RC, Giddens MM, Schaefer SA, Hall RA. GPR37 and GPR37L1 are receptors for the neuroprotective and glioprotective factors prosaptide and prosaposin. Proc Natl Acad Sci U S A. 2013; 110:9529-34.

28. Stein LM, Yosten GL, Samson WK. Adropin acts in brain to inhibit water drinking: potential interaction with the orphan G protein-coupled receptor, GPR19. Am J Physiol Regul Integr Comp Physiol. 2016; 310:R476-80.

29. Weiss KT, Fante M, Kohl G, Schreml J, Haubner F, Kreutz M, Haverkampf S, Berneburg M, Schreml S. Protonsensing $\mathrm{G}$ protein-coupled receptors as regulators of cell proliferation and migration during tumor growth and wound healing. Exp Dermatol. 2017; 26:127-132.

30. Dalm SU, Sieuwerts AM, Look MP, Melis M, van Deurzen $\mathrm{CH}$, Foekens JA, de Jong M, Martens JW. Clinical Relevance of Targeting the Gastrin-Releasing Peptide Receptor, Somatostatin Receptor 2, or Chemokine C-X-C Motif Receptor 4 in Breast Cancer for Imaging and Therapy. J Nucl Med. 2015; 56:1487-93.

31. Claringbold PG, Brayshaw PA, Price RA, Turner JH. Phase II study of radiopeptide 177Lu-octreotate and capecitabine therapy of progressive disseminated neuroendocrine tumours. Eur J Nucl Med Mol Imaging. 2011; 38:302-11.

32. Nieto Gutierrez A, McDonald PH. GPCRs: Emerging anticancer drug targets. Cell Signal. 2018; 41:65-74.

33. Arnold K, Bordoli L, Kopp J, Schwede T. The SWISSMODEL workspace: a web-based environment for protein structure homology modelling. Bioinformatics. 2006; 22:195-201.

34. Benkert P, Biasini M, Schwede T. Toward the estimation of the absolute quality of individual protein structure models. Bioinformatics. 2011; 27:343-50.

35. Biasini M, Bienert S, Waterhouse A, Arnold K, Studer G, Schmidt T, Kiefer F, Gallo Cassarino T, Bertoni M, Bordoli L, Schwede T. SWISS-MODEL: modelling protein tertiary and quaternary structure using evolutionary information. Nucleic Acids Res. 2014; 42:W252-8.

36. Kurcinski M, Jamroz M, Blaszczyk M, Kolinski A, Kmiecik S. CABS-dock web server for the flexible docking of peptides to proteins without prior knowledge of the binding site. Nucleic Acids Res. 2015; 43:W419-24.

37. Grosdidier A, Zoete V, Michielin O. SwissDock, a proteinsmall molecule docking web service based on EADock DSS. Nucleic Acids Res. 2011; 39:W270-7.

38. Grosdidier A, Zoete V, Michielin O. Fast docking using the CHARMM force field with EADock DSS. J Comput Chem. 2011; 32:2149-59.

39. Ingangi V, Bifulco K, Yousif AM, Ragone C, Motti ML, Rea D, Minopoli M, Botti G, Scognamiglio G, Fazioli F, Gallo M, De Chiara A, Arra C, et al. The urokinase receptor-derived cyclic peptide [SRSRY] suppresses neovascularization and intravasation of osteosarcoma and chondrosarcoma cells. Oncotarget. 2016; 7:54474-54487. https://doi.org/10.18632/oncotarget.9976.

40. Blake A, Dragan M, Tirona RG, Hardy DB, Brackstone M, Tuck AB, Babwah AV, Bhattacharya M. G proteincoupled KISS1 receptor is overexpressed in triple negative breast cancer and promotes drug resistance. Sci Rep. 2017; $7: 46525$.

41. Altschul SF, Madden TL, Schaffer AA, Zhang J, Zhang Z, Miller W, Lipman DJ. Gapped BLAST and PSI-BLAST: a new generation of protein database search programs. Nucleic Acids Res. 1997; 25:3389-402.

42. Remmert M, Biegert A, Hauser A, Soding J. HHblits: lightning-fast iterative protein sequence searching by HMM-HMM alignment. Nat Methods. 2011; 9:173-5.

43. Varambally S, Yu J, Laxman B, Rhodes DR, Mehra R, Tomlins SA, Shah RB, Chandran U, Monzon FA, Becich MJ, Wei JT, Pienta KJ, Ghosh D. Integrative genomic and proteomic analysis of prostate cancer reveals signatures of metastatic progression. Cancer Cell. 2005; 8:393-406.

44. Planche A, Bacac M, Provero P, Fusco C, Delorenzi M, Stehle JC, Stamenkovic I. Identification of prognostic molecular features in the reactive stroma of human breast and prostate cancer. PLoS One. 2011; 6:e18640.

45. Arredouani MS, Lu B, Bhasin M, Eljanne M, Yue W, Mosquera JM, Bubley GJ, Li V, Rubin MA, Libermann TA, Sanda MG. Identification of the transcription factor single-minded homologue 2 as a potential biomarker and immunotherapy target in prostate cancer. Clin Cancer Res. 2009; 15:5794-802.

46. Wang Y, Xia XQ, Jia Z, Sawyers A, Yao H, Wang-Rodriquez $\mathrm{J}$, Mercola D, McClelland M. In silico estimates of tissue components in surgical samples based on expression profiling data. Cancer Res. 2010; 70:6448-55.

47. Derosa CA, Furusato B, Shaheduzzaman S, Srikantan V, Wang Z, Chen Y, Seifert M, Ravindranath L, Young D, Nau M, Dobi A, Werner T, McLeod DG, et al. Elevated osteonectin/SPARC expression in primary prostate cancer predicts metastatic progression. Prostate Cancer Prostatic Dis. 2012; 15:150-6.

48. Mortensen MM, Hoyer S, Lynnerup AS, Orntoft TF, Sorensen KD, Borre M, Dyrskjot L. Expression profiling of prostate cancer tissue delineates genes associated with recurrence after prostatectomy. Sci Rep. 2015; 5:16018.

49. Karnoub AE, Dash AB, Vo AP, Sullivan A, Brooks MW, Bell GW, Richardson AL, Polyak K, Tubo R, Weinberg RA. Mesenchymal stem cells within tumour stroma promote breast cancer metastasis. Nature. 2007; 449:557-63.

50. Hawthorn L, Luce J, Stein L, Rothschild J. Integration of transcript expression, copy number and $\mathrm{LOH}$ analysis of infiltrating ductal carcinoma of the breast. BMC Cancer. 2010; 10:460.

51. Lopez FJ, Cuadros M, Cano C, Concha A, Blanco A. Biomedical application of fuzzy association rules for identifying breast cancer biomarkers. Med Biol Eng Comput. 2012; 50:981-90. 
52. Clarke C, Madden SF, Doolan P, Aherne ST, Joyce H, O'Driscoll L, Gallagher WM, Hennessy BT, Moriarty M, Crown J, Kennedy S, Clynes M. Correlating transcriptional networks to breast cancer survival: a large-scale coexpression analysis. Carcinogenesis. 2013; 34:2300-8.

53. Grinchuk OV, Motakis E, Yenamandra SP, Ow GS, Jenjaroenpun P, Tang Z, Yarmishyn AA, Ivshina AV, Kuznetsov VA. Sense-antisense gene-pairs in breast cancer and associated pathological pathways. Oncotarget. 2015; 6:42197-221. https://doi.org/10.18632/oncotarget.6255.

54. Lappano R, Maggiolini M. G protein-coupled receptors: novel targets for drug discovery in cancer. Nat Rev Drug Discov. 2011; 10:47-60.

55. Lappano R, Maggiolini M. Pharmacotherapeutic Targeting of G Protein-Coupled Receptors in Oncology: Examples of
Approved Therapies and Emerging Concepts. Drugs. 2017; 77:951-965.

56. Uemura H, Hasumi H, Kawahara T, Sugiura S, Miyoshi Y, Nakaigawa N, Teranishi J, Noguchi K, Ishiguro H, Kubota Y. Pilot study of angiotensin II receptor blocker in advanced hormone-refractory prostate cancer. Int J Clin Oncol. 2005; 10:405-10.

57. Liu Y, An S, Ward R, Yang Y, Guo XX, Li W, Xu TR. G protein-coupled receptors as promising cancer targets. Cancer Lett. 2016; 376:226-39. 